\title{
ELEMENTOS DE INSPIRACIÓN ORIENTALIZANTE EN LA CUENCA MEDIA DEL RÍO TAJO: EL YACIMIENTO DE "PUENTE LARGO DE JARAMA" (ARANJUEZ, MADRID)*
}

\section{ORIENTALISING-LIKE ELEMENTS FROM THE MIDDLE TAGUS BASIN: THE PUENTE LARGO DE JARAMA (ARANJUEZ, MADRID) SITE}

\author{
por \\ KENIA MUÑOZ LÓPEZ-ASTILLEROS \\ JOSÉ ORTEGA BLANCO
}

RESUMEN Se presentan algunos hallazgos efectuados en las prospecciones y excavaciones del yacimiento de la Primera Edad del Hierro de Puente Largo de Jarama (Aranjuez, Madrid): una casa cuadrangular de esquinas redondeadas con zócalo de piedra, suelo de arcilla quemada y enlucido de yeso; un vaso con decoración de lotos incisos; un soporte de carrete y una cazuelita o remate de timiaterio. Tras repasar los paralelos orientalizantes de estos elementos y otros similares documentados en la cuenca media del Tajo, se analizan dentro del contex to general del Hierro Antiguo de la región.

ABSTRACT This paper presents some elements found in the surveys and excavations carried out in the site called Puente Largo de Jarama (Aranjuez, Madrid): a round-cornered quadrangular house with a floor made of burnt clay and a walls plastered with gypsum; a vessel decorated lotus; a reel-shaped stand; and a possible carinated bowl or top of a thymiaterium. After reviewing other similar "orientalizing" elements from the middle basin of the Tagus river and the South of the Iberian peninsula, the relations and general context of the site are analysed.

\section{INTRODUCCIÓN}

Presentamos en este estudio un avance de los resultados de las excavaciones arqueológicas llevadas a cabo por uno de nosotros (K. Muñoz) en el yacimiento arancetano de Puente Largo de Jarama durante el año 1993. En el transcurso de dichos trabajos se exhumó parte de un edificio asignable a la Primera Edad

* Agradecemos a Gonzalo Ruiz Zapatero sus atinadas sugerencias y comentarios sobre este estudio. 
del Hierro por los paralelos de las cerámicas que proporcionó. La construcción en sí presenta, por su parte, unas características muy singulares, únicas por ahora en el ámbito madrileño, que la relacionan con ambientes "orientalizantes" del Mediodía peninsular. En las prospecciones complementarias se recuperaron materiales que redundan asimismo en este último sentido al tratarse, por lo que parece, de "versiones" de piezas propias de aquel ámbito ligadas igualmente con edificios de características y relevancia singulares. Todo ello nos lleva a proponer la hipótesis de que la construcción exhumada en Puente Largo debió constituir en su momento un edificio destacado y distinto, comprensible o explicable probablemente por su contigüidad a un vado del Jarama que ha constituido desde tiempo inmemorial paso y cruce fundamental de las vías naturales de comunicación del Tajo central.

\section{EL YACIMIENTO}

El yacimiento de Puente Largo de Jarama se sitúa en varias terrazas de la margen izquierda del río Jarama, escasos kilómetros aguas arriba de su confluencia con el río Tajo en la localidad madrileña de Aranjuez, a cuyo término municipal pertenece, y aguas abajo de su confluencia con el Tajuña en el pueblo madrileño de Titulcia (figs. 1-3).

El sitio recibe el nombre de la construcción de 1761 junto a la cual se localiza (Álvarez de Quindós 1804:281), sobre un vado natural ${ }^{1}$. Por dicho punto salvaban el río tanto el antiguo camino de Andalucía -después carretera nacional N-IV-como la Vereda Toledana -ramal de la Cañada Oriental Soriana entre Fuentidueña de Tajo y Toledo por la margen derecha del río Tajo-y el camino-cañada de Aranjuez a Titulcia -que desde tierras madrileñas sigue la margen izquierda del río Jarama- (fig. 3).

Los terrenos aluviales de vega junto a los que se ubica el yacimiento constituyen suelos inmejorables para el cultivo y los pastos (Jiménez de Gregorio 1962-1986:I-496; Porres y otros 1986:18; Madoz 18481850:II-442 y XIV-783; Evaluación de Recursos Agrarios 1982:15 ss.) (fig. 2). Estos suelos están bordeados por margas y yesos terciarios en los que abundan los manantiales de aguas salobres (Jiménez de Gregorio 1962-1986: I-126 y II-388; Porres y otros 1986: 71-72; Madoz 1848-1850: XIV-205; López y Arroyo 1983: 340-341) (fig. 3), cuyas sales son muy apropiadas para el alimento del ganado (López y Arroyo 1983:341) y poseen incluso propiedades medicinales (Leblic 1994:34-37). Algunos de estos manantiales han sido famosas explotaciones salineras -Valdeabejares, La Higuera, Las Salinillas y, sobre todo, Espartinas (fig. 3)que, aunque hoy se encuentren abandonadas, llegaron a ser fundamentales en el aprovisionamiento de sal de la Corona de Castilla, bajo cuya jurisdicción directa se encontraban desde época medieval (López y Arroyo 1983:342-347).

\section{PRIMEROS TRABAJOS ARQUEOLÓGICOS}

El yacimiento de Puente Largo era conocido por algunos materiales publicados por Pérez de Barradas en 1936, procedentes de la prospección superficial de unos "fondos de cabaña" que quedaron al descubierto en los taludes de una gravera. Se trataba de algunas vasijas carenadas lisas, a veces con mamelones de perforación horizontal, y otras decoradas con motivos incisos como retículas, zig-zags y triángulos rellenos de líneas paralelas. En las prospecciones realizadas en el año 1985 para la elaboración de la Carta Arqueológica

1. Esta circunstancia se repite en otros puentes de época moderna como el madrileño de San Fernando o de Viveros (San Fernando de Henares) sobre el Jarama (Bermejo y Muñoz 1995-1996). 
de la Comunidad de Madrid $^{2}$ se recogieron abundantes cerámicas a mano lisas, como cuencos, vasitos carenados, bases de talón, algún cuenco de ala plana, pies altos -incluido un hermoso pie de copa molduradoy grandes recipientes de superficies toscas o escobilladas, cuello indicado y borde vuelto con digitaciones -que eventualmente también se disponen en los cuellos-. De la parte baja del sitio proceden, en concreto, diversas piezas de industria lítica como dientes de hoz y láminas de sílex además de varias cerámicas a mano decoradas: algún fragmento indeterminado con restos de pintura roja; un galbo fino con una banda excisa sobre la que se destacan cuadrados tumbados rellenos de paralelas oblicuas incisas; dos galbos más gruesos y toscos con series de ángulos paralelos asimismo incisos; y un cuello de vasija con una franja de papiros confeccionados mediante incisión. De la parte alta del lugar procede, en cambio, la única pieza metálica recuperada en Puente Largo: una cazuelita carenada de bronce (fig. 5-A: 2).

\section{CAMPAÑA DE EXCAVACIÓN DE 1993}

Finalmente, en 1993 se realizó en Puente Largo una excavación arqueológica bajo la dirección de uno de nosotros (K. Muñoz) ${ }^{3}$ como parte de su citada Tesis Doctoral. Dicha campaña tenía como objetivos documentar la estructura de habitación visible en una zanja moderna que cortaba el yacimiento e identificar los materiales a ella asociados, así como realizar análisis palinológicos, paleocarpológicos, faunísticos y edafológicos y obtener dataciones radiocarbónicas; todo ello como aproximación a una caracterización material, habitacional, medioambiental y cronológica de la Primera Edad del Hierro en el Tajo central.

Durante los trabajos se excavó un área de aproximadamente $25 \mathrm{~m}^{2}$ perteneciente a un edificio de planta probablemente rectangular con los ángulos redondeados, sepultado por el derrumbe de sus muros. Éstos estaban constituidos en su parte inferior por un zócalo de piedras sobre el que se disponía un alma de maderos cubierta por adobes o tapial -alma que había dejado una zanja en el barro como impronta-, y enlucidos de yeso blanco ${ }^{4}$. Formaban el zócalo, de unos $50 \mathrm{~cm}$ de ancho, grandes cantos redondeados dispuestos en dos hiladas (fig. 6: 4). El suelo de la habitación estaba constituido por un lecho de guijarros pequeños cubiertos de una capa de arcilla endurecida por el fuego, del que quedaban restos en diversos puntos. Sobre dicho suelo y en un extremo de la cabaña se situaba un gran hogar pseudocircular de aproximadamente $1 \mathrm{~m}$ de diámetro, formado por un piso de cantos pequeños y medianos, cubiertos por una capa de fragmentos cerámicos y, sobre ella, un grueso paquete de arcilla rojiza quemada. Junto a este hogar, que había preservado bajo y en torno a él el tramo mejor conservado de suelo, se disponía un pequeño hoyo relleno de cenizas y algún hueso.

Las cerámicas recuperadas en la excavación, confeccionadas a mano y cocidas en su mayoría en una atmósfera reductora, son muy similares a las documentadas en las prospecciones precedentes (fig. 4). Entre aquéllas son asimismo minoría los pequeños vasitos decorados con bandas de diversos motivos incisos (fig. 4:6,9 y 10): únicamente nueve ejemplares en el cómputo total de fragmentos, de los cuales sólo tres proceden del interior de la cabaña y de ellos dos del encachado del hogar. Otras formas documentadas son bordes almenados, fragmentos cubiertos con almagra a veces de gran calidad, alguna "paellera", grandes

2. La Carta Arqueológica del término municipal de Aranjuez fue realizada bajo la dirección de F. Velasco, J. Baena, B. Martínez y P. Mena, quienes amablemente cedieron dicha información para la Tesis Doctoral que actualmente realiza uno de nosotros (Kenia Muñoz) bajo el título El poblamiento desde el Neolítico Final a la Primera Edad del Hierro en la cuenca media del río Tajo.

3. Dicha excavación, que mucho tuvo que agradecer a Manuel Fernández-Miranda ( $\dagger$ ), fue llevada a cabo con permiso y subvención de la Comunidad de Madrid y su publicación completa se encuentra en preparación por parte de la directora de los trabajos.

4. Agradecemos a Victor Manuel Valdés el análisis químico de dicho enlucido, cuyos resultados serán publicados junto con la Memoria de la excavación. 
vasos globulares de boca estrangulada y otros de superficies muy cuidadas y cuerpo carenado de perfil marcadamente bicónico. En superficie se recuperó también un soporte de carrete (fig. 5-A: 1).

El aplastante predominio de las formas lisas en el repertorio cerámico permite situar cronológicamente Puente Largo a medio camino entre aquellos yacimientos del Tajo central fechables en los siglos VIII y VII a.C., que han proporcionado recipientes carenados relativamente abundantes con decoración incisa, y aquellos otros, del siglo VI a.C., donde sólo se han recuperado barros lisos. Entre los primeros podemos citar Camino de las Cárcavas (Almagro y otros 1996; López y otros e.p.) y Cerro de San Antonio (Blasco y otros 1991), mientras que entre los segundos se encuentran los niveles antiguos de Las Madrigueras (Almagro-Gorbea 1969) y Los Pinos (Muñoz y Ortega 1996). O lo que es lo mismo, Puente Largo pudo ser contemporáneo de La Capellana de Pinto (Blasco y Baena 1989; Blasco y otros 1993), en donde escasean las especies decoradas con incisión y están presentes las almagras de calidad y que, pese a sus fechas de Termoluminiscencia de 528-516 a.C. (Blasco y otros 1993: 60 y 65-66), nos parece que podría ser algo más antiguo (Muñoz y Ortega 1996: 36-37).

Otros rasgos característicos de la cerámica de Puente Largo, como los pies altos, los cuencos de ala plana, los vasos de cuerpo globular y cuello estrangulado o las grandes vasijas de perfil bicónico son asimismo típicos de yacimientos del siglo VI a.C. del ámbito oriental de la Meseta (Almagro-Gorbea 1969; Aranda 1990; Cerdeño y García 1990; García-Carrillo y Encinas 1990; García-Soto 1990; García-Soto y Rosa 1995; Rosa y García-Soto 1995; Muñoz y Ortega 1996). Todo ello, junto con los datos que aportan los paralelos de los elementos "orientalizantes" recuperados en Puente Largo (vid infra), permiten sugerir para el sitio arancetano y para el edificio parcialmente exhumado una fecha de finales del siglo VII o comienzos del VI a.C.

\section{ELEMENTOS DE INSPIRACIÓN ORIENTALIZANTE DE PUENTE LARGO DE JARAMA}

\section{El vaso decorado con lotos incisos}

Entre los materiales documentados en la excavación apareció un fragmento de un vaso cerrado de gran tamaño, cuyo cuello estaba decorado mediante finas incisiones, representando motivos florales diestramente trazados con un esquema complejo que no puede ser considerado original, sino que se imitan diseños foráneos, pero, con toda seguridad, bien conocidos por el artesano. El fragmento conserva tres flores de loto abiertas, la central prácticamente entera y los extremos de otras dos. Las flores están compuestas por dos grandes pétalos que inscriben otros tres, de los cuales sólo el central está representado por una doble línea; bajo dicha franja aparecen restos de otro motivo que nos lleva a pensar quizá en la existencia de otra banda similar y, en suma, de una decoración más elaborada.

Lotos y papiros son motivos decorativos procedentes de Egipto, hábitat natural de estas plantas, en donde se vinculaban a cultos de Isis y a la inmortalidad del alma. Con este sentido se introduce en la iconografía y en la escatología fenicias, siendo los comerciantes fenicios los que difundieron estos motivos, a través de los cuales llegaron con seguridad a España. Los soportes son tan variados como las técnicas empleadas para sus representaciones. Así, contamos con lotos y papiros, bien solos o formando parte de escenas más complejas con animales, reales o fantásticos, sobre objetos de bronce, marfil, cerámica e incluso alguna representación en piedra.

Numerosos motivos florales se representaron sobre marfil, materia prima con la que se realizaban peines, paletas, píxides y otros objetos de lujo. La técnica empleada, en los ejemplares peninsulares, es la incisión, lo que les procura una apariencia más tosca que los orientales en los que encontramos sus más próximos precedentes iconográficos, como los hallados en Nimrud (Siria) (Mallowan 1966), delicadamente decorados 
en relieve. Sobre bronce tenemos varias representaciones de lotos o papiros, a menudo relacionados con representaciones de Astarté. Está presente, por ejemplo, en el tocado de la figurilla hallada en Cástulo (Blanco 1963: fig. 31); también como pectoral de la diosa en el «Bronce Carriazo» (Blanco 1963: fig. 34), o en el cuello del llamado «jarro Lázaro» (García y Bellido 1964: fig. 29) (fig. 5-B: 7).

También son relativamente frecuentes las cerámicas decoradas, tanto incisas como pintadas. Las cerámicas orientalizantes pintadas con motivos figurados, tanto animales como vegetales, han sido objeto de estudio en varias ocasiones (Pachón y otros 1989-90 con toda la bibliografía anterior). Se concentran en torno al valle medio del Guadalquivir, apareciendo algunos ejemplares en la campiña de Jaén y en el Sudeste. Se conocen ejemplares con decoraciones muy similares a la nuestra en lugares como Setefilla (Aubet 1982b:223), Carmona (Belén 1995) y Montemolín (Bandera y otros 1995). Los motivos son muy variados formando, en ocasiones, escenas complejas con animales reales y fantásticos rodeados de vegetación, como las halladas en 1992 en el barrio de San Blas de Carmona (Sevilla), donde aparece un vaso pintado con grifos que desfilan entre flores y capullos de loto y otros dos con un gran friso decorado con una cadena de flores abiertas y capullos de loto entrelazados (Belén 1995:22) (fig. 5-B: 6). Se fechan a mediados del siglo VII a.C.

Cerámicas incisas con motivos orientalizantes son realmente escasas en el Suroeste, pero hay que tener en cuenta que la incisión como técnica decorativa en cerámica de dicha época, además de estar en general muy escasamente representada y casi siempre con motivos geométricos, prácticamente desaparece a partir de inicios del siglo VII, cuando empiezan a decorarse vasos con motivos figurados ${ }^{5}$.

El único ejemplar con decoración de lotos conocido en la cuenca media del Tajo, además del que aquí presentamos, es un fragmento inciso procedente del yacimiento madrileño de Ecce Homo, en el valle del Henares (Almagro-Gorbea 1987:114).

Ejemplos de flores de loto incisas esquematizadas, de cronología tardía, aparecen también sobre algunos fragmentos de cerámica a mano del estrato antiguo del poblado de la Segunda Edad del Hierro del Cerro de las Nieves (Pedro Muñoz, Ciudad Real), publicados como del siglo VI o comienzos del V a.C. (Fernández y otros 1994: 121 y fig. 4).

También con motivos vegetales se decoran los huevos de avestruz, objetos orientalizantes de alto contenido simbólico relacionado con el mundo funerario (San Nicolás 1975:tabla IV, especialmente grupo 7). Encontramos estos objetos en tumbas tanto fenicias como indígenas, desde el siglo VIII a.C., aunque la muestra más numerosa procede de Villaricos (Astruc 1951), en donde han de fecharse entre los siglos VI y IV a.C.

Sobre las cáscaras de huevo de avestruz es interesante destacar !a decoración de sus bordes, que frecuentemente se recortan formando auténticos bordes almenados, otro elemento escaso en número pero muy característico de las cerámicas de la Meseta de este periodo. Estas cerámicas podrían ser imitaciones de los huevos. como se ha propuesto para las cerámicas de bordes dentados de Levante (Fletcher 1953: 9 fig. 14).

\section{El soporte de carrete con baquetón circular}

Forma desconocida hasta ahora en el Centro de la península, son objetos frecuentes en poblados del Bronce Final del Suroeste (Gassul 1982). De prototipo fenicio, está formado por dos troncos de cono modelados a mano y unidos por sus partes más estrechas. Generalmente en la zona de unión se le añade uno o

5. Hay ejemplos de vasos decorados con incisión contemporáneos a las cerámicas pintadas, y más recientes, aunque el haber sido grabados, en la mayor parte de los casos, después de la cocción, así como los propios diseños de los motivos, nos hace pensar que, salvo excepciones, no se trataría de decoraciones en sentido estricto, sino más bien, marcas de propietario o de uso, lo que hace que en ocasiones se hayan estudiado junto a las inscripciones. 
varios baquetones, que suelen desaparecer en las producciones a torno. D. Ruiz Mata (1979 y 1995) advierte la tendencia regional de los poblados del Bajo Guadalquivir al baquetón redondeado, siendo propio de los del área onubense el baquetón con arista. A partir del siglo VII a.C. se aprecia una tendencia a la estilización, así como a una reducción de los diámetros de la zona central, especialmente en los fabricados a torno (fig. 5-A: 1)

\section{La cazuelita carenada de bronce ${ }^{6}$}

Por lo que respecta a la cazuelita de bronce poco podemos avanzar debido al escaso conocimiento de la pieza, a la que sólo conocemos por su dibujo. Llama la atención lo peculiar del material, muy poco frecuente en vajillas de la Protohistoria peninsular, y que generalmente aparecen en contextos funerarios. Tipológicamente hablando, los pocos ejemplares conocidos corresponden a tres grupos generales: cuencos hemiesféricos con el borde recto o ligeramente entrante o engrosado, como los hallados en Baiões (Coelho y otros 1984); otros, como el de Berzocana (Callejo y Blanco 1960:251) o el del Túmulo H de Setefilla (Aubet 1973:12), tienen el borde saliente y una suave carena, mientras que el procedente de la tumba 14 de La Joya (Garrido y Orta 1978:42) presenta un perfil escalonado con triple carena. Es a este último al que más se asemeja nuestro ejemplar, y aunque el vaso de Puente Largo sólo tiene una carena, al estar fragmentado, no podemos asegurar que no tuviera algún otro cambio de dirección en la parte inferior. (fig. 5-B: 2)

Por otra parte, al no tener detalle de la técnica de producción-fundido, martilleado, batido o remachado de láminas- no podemos asegurar ni su cronología ni su uso, sin descartar que podría formar parte de un objeto de mayor tamaño, ya que su perfil corresponde grosso modo con los de la parte superior de timiaterios como el de la tumba 17 de La Joya (Huelva) (Garrido y Orta 1978:91 y fig. 58), o el más próximo de Las Fraguas (Toledo) (Fernández-Miranda y Pereira 1992; Pereira 1994). Del Camino Pucheros (fig. 3), próximo a Puente Largo, procede asimismo un fragmento muy deteriorado, que posiblemente corresponde a otro recipiente metálico parecido, así como una placa con remache, quizá perteneciente a un brasero.

\section{La estructura de habitación ${ }^{7}$}

Como ya hemos indicado, la excavación realizada permitió documentar el sector nororiental de una gran sala de más de $25 \mathrm{~m}^{2}$. No se pudo excavar el edificio completo, por lo que no sabemos sus dimensiones totales ni otros aspectos como acceso o distribución interior, pero sí conocemos elementos muy significativos como la presencia de ángulos redondeados en las esquinas, zócalo pétreo, enlucidos exteriores de yeso, suelo de guijarritos cubiertos de arcilla apisonada y endurecida por el fuego, y hogar circular de similar composición, salvo por la presencia de un piso intermedio de fragmentos cerámicos.

Esta técnica constructiva convierte a la casa de Puente Largo en un ejemplạr excepcional en el panorama de las estructuras de habitación de la Primera Edad del Hierro localizadas hasta ahora en la cuenca media del Tajo, puesto que éstas están construidas en todos los casos con materiales perecederos sin zócalos de piedras -salvo quizá en La Capellana-ni suelos de arcilla prensada ni hogares tan complejos, y frecuentemente presentan plantas ovales (fig. 7). En la Zona B del Sector III de Getafe (Madrid) se documentó una cabaña

6. Agradecemos a Javier Jiménez Ávila sus observaciones sobre este tipo de piezas.

7. Agradecemos a Concepción Blasco y a Antonio Dávila su ayuda en la localización de alguna bibliografía especializada sobre viviendas de la Edad del Hierro. 
de planta oval excavada en el suelo y rodeada de agujeros de poste en los que se sujetarían paredes de materiales perecederos y un techo de tramado vegetal manteado de barro (Blasco y Barrio 1986). En la Muela de Alarilla se recuperó una cabaña circular asignable al Bronce Final, de gran diámetro y alzado ligero, delimitada por piedras y por varios hogares (Méndez y Velasco 1984). Las dos estructuras localizadas en Cerro de San Antonio, fechadas en el siglo VII a.C., presentan también plantas de tendencia circular (fig. 7:3 y 4), quizá compartimentadas interiormente y con un porchecito de entrada, con suelos de guijarros o tierra batida y hogares apenas preparados, y confeccionadas con débiles alzados de ramaje y barro (Blasco y otros 1991). Muy similares son las cabañas de Los Pinos: de planta oval semiexcavada en el suelo y delimitada por agujeros de poste, y una de ellas, con hogar central (fig. 7: 1 y 2). Sus niveles inferiores han sido fechados en el siglo VI a.C., mientras que en los superiores aparecen ya las primeras cerámicas a torno (Muñoz y Ortega 1996). Finalmente, en Ecce Homo (Alcalá de Henares, Madrid) también se documentó una cabaña excavada en la roca rodeada de hoyos de poste (fig. 7:6), aunque su estructura sería totalmente de madera, lo cual constituye un caso excepcional en la zona. Tendría planta oval que fue modificada en una segunda fase a rectangular con compartimentos internos; el acceso se haría mediante una rampa y tendría un escalón interior constituido por la propia roca a modo de banco corrido (Almagro y Dávila 1988).

Las únicas estructuras cuadrangulares asignables a la Primera Edad del Hierro documentadas en el área de estudio o en zonas vecinas, además de la segunda fase de Ecce Homo y la que aquí presentamos, serian las de Arenero de Soto II (Getafe, Madrid), Pico Buitre (Espinosa de Henares, Guadalajara) y quizá La Capellana (Pinto, Madrid). En el Arenero de Soto II se documentaron improntas de muros rectilíneos y en ángulo rellenos de arenas muy finas así como encachados circulares de cantos de río quemados y acumulaciones de adobes, pertenecientes a dos cabañas de la transición entre la Edad del Bronce y la del Hierro (Pernia y Leira 1992). En Pico Buitre se documentó al menos una pared recta que doblaba en ángulo, constituida por un zócalo de tapial sobre el que se alzaría un entramado de ramas y troncos, cubiertos ambos de un manteado calizo; paralelas a ella se localizaron líneas de piedras en distintos niveles, quizá pertenecientes a compartimentaciones internas, así como diversas placas de arcilla cocida (Crespo 1995). En La Capellana se documentó un zócalo o murete recto compuesto con grandes bloques de sílex, fechado ya en el siglo VI a.C. (Blasco y Baena 1989).

Por el contrario, en yacimientos de "Campos de Urnas" del valle del Ebro se han documentado viviendas rectangulares con zócalo de piedra, alzados de adobe, bancos corridos de barro y pavimentos de arcilla apisonada apoyada a veces sobre un piso de cantos rodados, que aparecen divididas en dos estancias (Ruiz Zapatero 1985). Faltan en ellas, no obstante, los ángulos redondeados documentados en Puente Largo, yacimiento este último donde, sin embargo, no se ha podido documentar, al menos en el área excavada, la existencia de compartimentación interior

Es, sin embargo, en las construcciones orientalizantes del Suroeste y Levante donde encontramos los paralelos más próximos en viviendas de planta cuadrada con ángulos redondeados. En el yacimiento gaditano de El Campillo (López y otros 1996) se documentó una estructura semiexcavada en el suelo de la marisma, de forma rectangular con las esquinas redondeadas, de $6 \times 4 \mathrm{~m}$. Sin embargo, los restos de enlucidos y estucos, formando ángulos rectos, hacen pensar que, al menos al interior, las paredes serían rectas. Éstas estarian constituidas por un entramado vegetal cubierto por tapial, del que se recogieron varios fragmentos pintados con ocre, sin postes de sustentación. El suelo estaría formado por una capa uniforme de piedras de pequeño tamaño, regularizados con arena y sobre el que se extendió una o varias capas de arcilla. Los investigadores que realizaron el estudio plantean la posibilidad de que presentara una compartimentación interna, que tendría su ratificación en la abundancia de conchas exhumadas, que podrían formar parte del suelo de una segunda estancia. Los autores citados la relacionan con los primeros contactos entre indígenas y los pueblos orientales, como quedaría demostrado por su cultura material, ya que entre los restos hallados se encuentran cerámicas chipriotas de tradición micénica (ss. X-IX a.C.) y vasos de Samaria (ss. IX-VIII a.C.). 
En Acinipo (Ronda, Málaga) se han excavado varias estructuras del Bronce Final, con zócalo de piedra y alzados de tapial, de planta circular u oval junto a otras de planta rectangular, entre las que se localizó una de unos $6 \mathrm{~m}^{2}$. de planta cuadrada con las esquinas redondeadas (fig. 6: 1), cuyo origen se ha relacionado con los primeros contactos de gentes de este área con grupos orientales (Aguayo y otros 1986 y 1991).

Otro paralelo muy próximo de la casa excavada en Puente Largo de Jarama lo constituye la denominada «vivienda metalúrgica» del estrato IIa de la Peña Negra (Crevillente, Alicante) (fig. 6: 2) fechada en la segunda mitad del siglo VIII a.C. (González Prats y Ruiz-Gálvez 1986; González-Prats 1992). Esta estructura, de $8 \times 4,5 \mathrm{~m}$, estaba constituida por amplios muros rectos con ángulos curvos hechos de arcilla roja sobre zócalo de doble hilera de piedras hincadas de $1 \mathrm{~m}$ de ancho. En su interior se documentaron dos estructuras, una cuadrangular de arcilla roja con dos orificios para postes, y otra circular con agujero central, que sería un horno de fundición de metal. Bajo el suelo, de lechadas superpuestas de caolín, se encontró una inhumación infantil y un pequeño ovicáprido sin cabeza. En los niveles previos las casas eran cabañas circulares u ovales excavadas en el suelo con hogares de arcilla apisonada quemada, rodeados de piedras, y viviendas circulares con paredes de arcilla roja similares a las de Soto de Medinilla, cuyos materiales se relacionan con los recuperados en el yacimiento de Cerro de San Antonio. En los niveles suprayacentes las viviendas son ya cuadrangulares con zócalo de piedras trabadas con barro, similares a las de otros poblados levantinos y meridionales (González Prats 1983; 1985 y 1992; Blasco y otros 1993).

En las excavaciones llevadas a cabo en 1992 en el barrio de San Blas de la localidad sevillana de Carmona, se localizó una sala rectangular de 4,40 x 1,80 m que formaba parte de un edificio de planta cuadrada cuyas características de construcción, especialmente cuidadas, hacen pensar a sus excavadores en un uso religioso (Belén 1995). Los muros están formados por un zócalo de piedra y alzado de adobe, revestidos de estucos pintados en rojo, y suelos de arcilla apisonada y endurecida. De su interior proceden tres grandes vasos, fabricados a torno, sobre los que se pintaron motivos orientalizantes, uno de los cuales consiste en "grifos que desfilan ... en un ambiente nilótico en el que las flores y los capullos de loto brotan por todos lados" (Belén 1995:22) y los otros están decorados con un gran friso con una cadena de flores abiertas y capullos de loto entrelazados. El conjunto se fecha en la segunda mitad del siglo VII a.C.

\section{LOS ELEMENTOS DE INSPIRACIÓN ORIENTALIZANTE DE "PUENTE LARGO DE JARAMA" EN EL CONTEXTO DE LA CUENCA MEDIA DEL RÍO TAJO}

Los elementos de inspiración orientalizante documentados en el yacimiento de Puente Largo de Jarama forman parte de una serie de piezas de similar raigambre que se han documentado o revisado en los últimos años en diversos puntos de la cuenca media del Tajo (fig. 2), y cuya aparición habría que relacionar con el papel jugado por el hinterland extremeño y la cuenca media del Guadiana como intermediarios del área nuclear tartésica. Por otra parte, estas conexiones con el Suroeste no constituyen tampoco una novedad en la Prehistoria del área de estudio, pudiendo rastrearse con claridad al menos desde el Calcolítico, sal vando las lógicas distancias (Muñoz y otros 1995; Garrido y Muñoz e.p.).

La pieza más antigua de las características citadas es el puñal del Carpio del Tajo o de Ronda (Mesegar de Tajo, Toledo) (Jiménez de Gregorio 1966:179), de tipo "lengua de carpa" y fechable, por tanto, en el siglo IX a.C., que revelaría, junto con otras piezas como las espadas de Sigüenza (Almagro 1940), la penetración de la metalurgia de tipo "Ría de Huelva" en el interior peninsular siguiendo los valles fluviales (Coffyn 1985:207; Fernández-Miranda y Pereira 1992:60; Galán y Ruiz-Gálvez e.p.).

De cronología similar, entre los siglos IX y VIII a.C., es la fíbula de codo ad occhio de Perales del Río (Getafe, Madrid)(Blasco 1987:20), cuyos paralelos más próximos, atlánticos y mediterráneos, se encuentran en el yacimiento portugués de Roça do Casal do Meio (Spindler y otros 1973-74) y en el levantino de la Mola 
d'Agres (Gil-Mascarell y Peña 1989). La pieza madrileña, aparecida en las proximidades de un vado, ha sido puesta en relación con el entramado de vías de comunicación y pasos de la época (Galán y Ruiz-Gálvez e.p.).

En estas fechas podría situarse también la estela de Las Herencias (Fernández-Miranda 1986), relacionada por su proximidad tipológica y geográfica con las cacereñas de Solana de Cabañas y Torrejón el Rubio (Fernández-Miranda y Pereira 1992:62). Sin ser propiamente un elemento orientalizante, formaría parte de un conjunto de manifestaciones similares que delimitarían claramente el hinterland tartésico. Reconocida desde antiguo su relación con zonas estratégicas de paso entre distintas áreas geográficas (Fernández-Miranda y Pereira 1992:62-63), se las ha identificado en fechas recientes con hitos y marcadores territoriales dentro del citado hinterland (Galán 1993).

Fechas ligeramente posteriores pueden proponerse para la decoración cerámica de botones de bronce incrustados, documentada en el valle del Tajo en los yacimientos toledanos de Carpio de Tajo (Belvis de la Jara) (Pereira y Álvaro 1988: fig. $2 \mathrm{n}^{\circ}$ 7) y Camino de los Pucheros 1-Peña Acirate (Borox) (Muñoz 1993: fig. $7 \mathrm{n}^{\circ} 12$ ), ambos con cerámicas a mano, que han sido fechados en el siglo VII a.C. (Pereira 1990; Pereira y Álvaro 1990; Muñoz 1993:330; Pereira 1994:60) pudiendo retrotraerse, desde nuestro punto de vista, incluso a fines del siglo VIII a.C. Estos dos hallazgos, junto con el de Alarcos (Ciudad Real), en la cuenca media del Guadiana, acompañado de cerámicas a torno (Fernández y otros 1995:33), son, por ahora, los hallazgos más septentrionales de este tipo decorativo, y podrían ser precedentes de sistemas decorativos similares de Cogotas II (Cabré 1931), como han señalado Pereira y Álvaro (1990:223). Los ejemplares meridionales más antiguos están en el cordobés Llanete de los Moros (Montoro, Córdoba)(Martín de la Cruz 1987:205, fig $21, n^{\circ} 144$ y $35, n^{\circ} 322$ ) y en el área granadina, en un horizonte del Bronce Final, asociados a cerámicas de retícula bruñida, cerámicas pintadas bícromas y fíbulas de codo (Molina y otros 1983), fechables alrededor del siglo VIII a. C., fecha en la que aparecen también en los túmulos A y B de Setefilla (Aubet 1975 y 1978b; Torres 1996); en Medellín son algo más tardías (s. VII a.C.), aunque también van acompañadas de piezas con decoración bruñida (Amo 1973).

El citado enterramiento de Carpio de Tajo (Belvis de la Jara, Toledo)(Pereira y Álvaro 1988 y 1990; Pereira 1990) constituye uno de los conjuntos orientalizantes más completos hallados en la cuenca media del río Tajo. Constituido por tres niveles escalonados, presentaba en el inferior una urna bruñida y pintada en negro con tres asas geminadas, con claros precedentes en el mundo orientalizante, dentro de la cual apareció una ampolla decorada con incrustaciones de botones de bronce y un alabastrón a mano que imita formas fenicias bien documentadas en Andalucía y Levante. Otros objetos eran un garfio de un broche de cinturón, fragmentos de una fíbula, dos fragmentos de hierro, restos de un brasero y un vaso de plata. En el segundo escalón aparecieron los restos de dos inhumados, un individuo adulto femenino y un niño, y en el superior, un conjunto de cuencos decorados con motivos geométricos pintados en dos colores una clepsidra, seis grandes urnas, anillos y un brazalete de bronce. Esta tumba, datada en la segunda mitad del siglo VII a.C. (Pereira 1990; Pereira y Álvaro 1990; Pereira 1994) e inicios del VI a. C. (FernándezMiranda y Pereira 1992), ha sido identificada como perteneciente a una mujer de "rango principesco" y su hijo (Fernández Miranda y Pereira 1992 70-72). Ruiz-Gálvez (1992 y 1993) va más allá al sugerir que se trata de una "princesa tartésica" casada con un gran personaje del hinterland como parte de una red de pactos e intercambios matrimoniales destinada a asegurar las buenas relaciones entre ambas zonas.

El ajuar funerario de Las Fraguas (Las Herencias, Toledo)(Fernández-Miranda y Pereira 1992), recuperado en un cerro próximo al que proporcionó la estela de Las Herencias y al poblado de Arroyo Manzanas (Moreno 1990) ${ }^{8}$, está compuesto de varios objetos de bronce: un jarro, un caldero y un timiaterio. El jarro debe corresponderse con el hoy depositado en el Metropolitan Museum de Nueva York, según el dibujo de Jiménez

8. En este poblado se ha recuperado cerámica con decoración bruñida (Moreno 1990:278), también ligada al mundo orientalizante. No obstante, carecemos de información precisa sobre el contexto material en el que aparece.

ISSN: 1133-4525 ISSN-e: 2255-3924

SPAL 6 (1997)

http://dx.doi.org/10.12795/spal.1997.i6.09 
de la Llave recogido por Maroto (1990:212); la parte superior del asa está decorada con tres serpientes, motivo que se repite de forma idéntica en el jarro de Niebla. El timiaterio, por lo que conocemos, parece muy similar al de Cástulo, y el caldero se ha paralelizado con los de Torres Vedras y la Aliseda (FernándezMiranda y Pereira 1992:64-65). El conjunto, que ha sido relacionado también con el control de lugares de paso (Fernández-Miranda y Pereira 1992:71; Galán y Ruiz-Gálvez e.p.), se ha fechado en la segunda mitad del siglo VII a.C. (Fernández-Miranda y Pereira 1992:66), aunque una revisión de los datos permitiría atribuirle una fecha más antigua, quizá dentro del siglo VIII a.C.

Las dos fíbulas de Azután (Jiménez de Gregorio 1955), por su parte, proceden de un enterramiento descubierto cerca del Carpio del Tajo, y se supone que acompañaban a dos vasijas con cenizas y varios huesos. Por su tipología y paralelos han sido fechadas a principios del siglo VI a.C. (Fernández-Miranda y Pereira 1992:70).

Desconocemos en detalle el contexto que acompañaba a la pieza cerámica decorada con lotos incisos procedente del cerro del Ecce Homo (Almagro-Gorbea 1987:114), aunque es verosímil pensar que se asocie a los niveles de la Primera Edad del Hierro del yacimiento.

Otros elementos documentados en la cuenca media del río Tajo para los que se ha propuesto o se podría proponer una relación más o menos estrecha con el "fenómeno orientalizante" son las decoraciones "a la almagra" y los "bordes almenados". Los baños "a la almagra" de los yacimientos de la cuenca media del Tajo se han considerado imitaciones de las cerámicas a torno de barniz rojo de talleres fenicios peninsulares (Blasco y otros 1993:57) e indígenas (López y otros e.p.).

Quizá habría que relacionar también con el mundo orientalizante las lengüetas verticales o "almenas" que se documentan sobre el borde de algunas vasijas de los yacimientos madrileños de Cerro de San Antonio (Blasco y otros. 1991: figs. $16 \mathrm{n}^{\circ} 10$ y $65 \mathrm{n}^{\circ} 15$ ) y Puente Largo de Jarama (fig. 4: 3). Nunca se ha recuperado un vaso completo de estas características, pero parecen presentar siempre un ligero perfil en " $S$ ". Las citadas autoras recogen, además, la presencia de este tipo de bordes en el yacimiento levantino de Peña Negra de

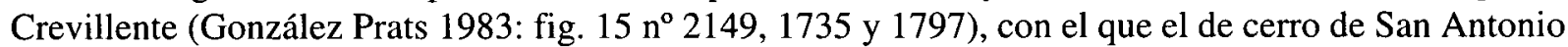
guardaría muchas analogías en el ámbito material (Blasco y otros 1993:56). Un borde decorado con almenas pintadas en rojo se ha documentado en Cástulo (Blázquez y Valiente 1981: fig 141. n 1198) y motivos pintados, acanalados e incisos "en meandro" han aparecido también en Carpio de Tajo (Pereira y Álvaro 1990: fig. 3), Cerro de San Antonio (Blasco y otros 1991: figs. $17 \mathrm{n}^{\circ} 5$ y $58 \mathrm{n}^{\circ}$ 5) y Camino de las Cárcavas (Aranjuez) (López y otros e.p.) respectivarnente, relacionados los primeros con el mundo geométrico (Pereira 1994:70) y los segundos con modelos de Campos de Urnas recientes (Blasco y otros 1991:116). Sin embargo, quizá no habría que desestimar el posible parentesco de los bordes "almenados" con los bordes dentados de los huevos de avestruz (San Nicolás 1975) que Fletcher asocia a los vasos ibéricos de los siglos V-I a. C.

Finalmente, sólo conocemos por una breve referencia la existencia de una pequeña placa de bronce calada y con decoración troquelada procedente de Los Llanos II-Venta de la Victoria (Getafe, Madrid) que, según sus publicadoras (Blasco y otros e.p., cit. en Sánchez-Capilla y Calle 1996), se relacionaría con el mundo orientalizante del Sureste peninsular.

\section{VALORACIÓN FINAL}

Lo excepcional del conjunto de Puente Largo de Jarama reside no sólo en lo poco corriente de la arquitectura, casi un unicum en la cuenca media del Tajo y el valle del Henares en esta época, sino además en los materiales asociados (Ruiz Zapatero y Lorrio 1988; Blasco y otros 1988; Blasco y otros 1991; Blasco y otros 1993; Muñoz 1993; López y otros e.p.; Almagro y Fernández-Galiano 1980; Valiente 1984; Crespo 1995). Incluso se puede considerar de especial interés su localización. La asociación de lugares con especial 
importancia, bien económica, bien social o religiosa, con edificios de mayor entidad, con factura más cuidada y, singularmente, de planta cuadrada con zócalo de piedra, alzados de adobe o tapial y suelos de arcilla prensada y endurecida por calor, se documentan con cierta profusión en el área nuclear tartésica. No faltan, sin embargo, ejemplos en las áreas periféricas, como el excavado en la Muela de Cástulo (Blázquez y Valiente 1981; Blázquez y otros 1985). También en el caso de la "vivienda metalúrgica" de La Peña Negra de Crevillente nos encontramos ante un edificio destinado a una actividad específica y especial (Ruiz-Gálvez 1993), no carente de contenido mágico, incluso sacro, como es la metalurgia.

En algunos casos, como en Carmona (Belén 1995), Montemolín (Bandera y otros 1995) o Huelva (García Sanz 1990), donde se ha podido documentar este tipo de edificios, éstos se relacionan con actividades religiosas (Belén 1995; Garrido y Ortega 1994). También se ha propuesto su uso como residencia palacial, incluso manteniendo un cierto carácter sacro, donde se rendiría culto a los antepasados de ciertos linajes aristocráticos, como pudo suceder en Cancho Roano (Almagro Gorbea 1993).

Además de su situación preferente dentro del poblado, estos «edificios públicos» han sido recientemente relacionados con materiales cerámicos singulares, generalmente vasos cerrados que, curiosamente, están decorados con motivos animalísticos y vegetales, entre los que destacan, por encima de cualquier otro, las flores de loto. En los casos en los que se ha podido documentar la forma completa, como en Carmona, los vasos no tenían la base plana. por lo que se hacía necesario el uso de soporte 0 , como en ese caso, estar embutido en un agujero en el suelo (Belén 1995).

Todo ello hace pensar que en el caso de Puente Largo nos encontraríamos también ante un edificio de características especiales, a lo que debemos añadir la posible existencia, en la parte alta del yacimiento, donde se recuperó el cuenco carenado metálico anteriormente mencionado, de algún tipo de recinto o depósito. Podríamos pensar en la presencia de, al menos, un personaje de alto rango que quiere hacer ostentación de su posición destacada utilizando una parafernalia orientalizante con toda su carga simbólica. Tal vez no se tratara tanto de un personaje principesco tartésico, como se ha sugerido para la dama enterrada en Carpio de Tajo, mucho más próximo, o quizá, formando parte del hinterland tartésico, sino de un poderoso personaje local que quiere legitimar su poder mediante símbolos -más bien versiones locales de símbolosde poder (¿político? ¿religioso? ¿ritual?) de clara raíz orientalizante. Es posible incluso que nos encontremos ante un intento de establecimiento de un linaje en el poder, que vendría demostrado por la recuperación de un posible ajuar funerario igualmente orientalizante pero anterior, o quizá posterior, en la parte alta del yacimiento.

Pero ¿por qué semejante intento de institucionalización en este punto concreto de la cuenca del río? o lo que es lo mismo ¿en qué se fundamentaría el poder económico, social, político o religioso -si fuera posible separar alguno de estos aspectos-del citado personaje o de su linaje? Desde nuestro punto de vista, es el control del vado del río junto al que se sitúa el poblado, así como la proximidad de las minas de sal, lo que permite explicar el edificio y su significado. Como expusimos más arriba, dicho vado constituye un paso fundamental sobre el Jarama desde antiguo. En efecto, es en dicho paso, a medio camino entre las confluencias del Jarama con el Tajuña y con el Tajo, donde confluyen diversas vías de comunicación que corresponden con sus respectivos valles (fig. 3) -el camino-cañada de la margen izquierda del Jarama y la Vereda Toledana de la margen derecha del Tajo- y que unen, en última instancia, el Alto Tajo con la Meseta Norte y el valle medio del Ebro a través de los pasos del Sistema Central e Ibérico. No se trata de que las vías ganaderas se hayan mantenido intactas desde hace milenios, pero sí que siguen caminos naturales relevantes, lo que vendría demostrado por el vacío arqueológico del interfluvio Tajo-Jarama en favor de este paso situado más al Norte (fig. 3)

Por dicho paso transitarían mercancías, ganados y personas procedentes de diversos puntos de la cuenca media y alta del Tajo en dirección hacia Extremadura y Andalucía, de donde procederían los elementos orientalizantes asimilados en Puente Largo. En este mismo sentido se ha interpretado la presencia de piezas 
metálicas idénticas a otras de Cortes de Navarra o de elementos cerámicos de tradición de Campos de Urnas en el vecino yacimiento de Camino de las Cárcavas (López y otros e.p.). Tampoco sería desdeñable el papel que pudo jugar el vado en el trasiego trasterminante de ganados en ambas direcciones o hacia manantiales salinos próximos (fig. 3) fundamentales en cualquier economía con importante componente ganadero (Escacena y Rodríguez 1988; Delibes 1993; Muñoz 1993; Blasco y otros 1994).

\section{BIBLIOGRAFÍA}

AGUAYO, P.; CARRILERO, M.; FLORES, C y TORRE, M.P. de la (1986): "El yacimiento pre y protohistórico de Acinipo (Ronda, Málaga): un ejemplo de cabañas del Bronce Final y su evolución”, Arqueología Espacial 9:33-58.

AGUAYO, P.; CARRILERO, M. y MARTÍNEZ, G. (1991) "La presencia fenicia y el proceso de aculturación de las comunidades del Bronce Final en la depresión de Ronda", Atti del II Congresso Internazionale di Studi Fenici e Punici (Roma 1987), II:559-572.

ALMAGRO, M. (1940): "La Ría de Huelva y el Final de la Edad del Bronce en Europa", Ampurias II:85-143.

ALMAGRO-GORBEA. M. (1969): La necrópolis de Las Madrigueras, Carrascosa del Campo (Cuenca). Biblioteca Praehistorica Hispana X. Madrid.

ALMAGRO-GORBEA. M. (1977): El Bronce Final y el Periodo Orientalizante en Extremadura. Biblioteca Praehistorica Hispana XIV. Madrid.

ALMAGRO-GORBEA. M. (1987): "El Bronce Final y la Edad del Hierro". 140 Años de Arqueología Madrileña: 108-119. Madrid.

ALMAGRO-GORBEA. M. (1987): "Tarteso desde sus áreas de influencia. La sociedad palacial en la Península Ibérica”. J. Alvar y J.M. Blázquez Tarteso y sus problemas : 108-119. Madrid.

ALMAGRO-GORBEA, M. y DÁVILA, A. (1988): "Estructura y reconstrucción de la cabaña Ecce Homo 86/6", Espacio. Tiempo y Forma 1:361-374.

ALMAGRO-GORBEA, M. y FERNÁNDEZ GALIANO, D. (1980): "Excavaciones en el Cerro Ecce Homo (Alcalá de Henares, Madrid)", Arqueología 2.

ALMAGRO-GORBEA, M.; LÓPEZ, L.; MADRIGAL, A.; MUÑOZ, K. y ORTIZ, J.R. (1996): “Antropomorfo sobre cerámica de la I Edad del Hierro de la Meseta", Complutum 7:141-146.

ÁLVAREZ DE QUINDÓS, J.A. (1804): Descripción histórica del Real Bosque y Casa de Aranjuez dedicada al Rey Nuestro Señor, Imprenta Real (Ed. Facsímil de ediciones Doce Calles, 1993).

AMO, M. de (1973): "Cerámicas de retícula bruñida de Medellín", XII Congreso Nacional de Arqueología (Jaén 1971): 375-388. Zaragoza.

ARANDA, A. (1990): "Necrópolis celtibéricas en el Bajo Jiloca”, Necrópolis celtibéricas. II Simposio sobre Celtíberos: 101-109. Zaragoza.

ASTRUC, M. (1951): La necrópolis de Villaricos, Informes y Memorias, 25, Madrid.

AUBET M.E. (1973): "Materiales púnico-tartesios de la necrópolis de Setefilla en la Colección Bonsor", Boletín del Seminario Español de Arte y Arqueología XXXII: 5-30.

AUBET, M. E. (1975): La necrópolis de Setefilla. Lora del Río, Sevilla. Túmulo A. P.I.P. II, Barcelona. AUBET M. E. (1978a): "Marfiles fenicios del Bajo Guadalquivir I.- Cruz del Negro", Boletín del Seminario Español de Arte y Arqueología XLIV: 5-30.

AUBET, M. E. (1978b): La necrópolis de Setefilla. Lora del Río, Sevilla. Túmulo B. P.I.P. III, Barcelona.

AUBET M. E. (1980): "Marfiles fenicios del Bajo Guadalquivir II.- Acebuchal y Alcantarilla", Boletín del Seminario Español de Arte y Arqueología XLVI: 32-92.

AUBET M. E. (1982a): "Marfiles fenicios del Bajo Guadalquivir III.- Bencarrón, Santa Lucía y Setefilla", Pyrenae 17-18: 231-279. 
AUBET, M. E. (1982b): Cerámicas polícromas con motivos figurados de Setefilla, Homenaje a Conchita Fernández Chicarro: 221-225. Madrid.

BANDERA, M.L. de la; CHAVES, F.; FERRER, E. y BERNÁLDEZ, E. (1995): “El yacimiento tartésico de Montemolín", Tartessos 25 años después. Actas del Congreso Conmemorativo del V Symposium Internacional de Prehistoria Peninsular:315-332. Jerez de la Frontera.

BELÉN, M. (1995): “Carmona Prerromana. Nuevos datos para la historia de la ciudad durante el I Milenio a.C.”. Leyenda y Arqueología de las ciudades prerromanas de la Península Ibérica IIII:17-32 . Madrid.

BERMEJO. J.L. y MUÑOZ. K. (1995-1996): "El yacimiento medieval de 'Vereda del' o 'Las Fuentecillas' (San Fernando de Henares, Madrid), campañas de 1989 y 1990”, Estudios de Prehistoria y Arqueología Madrileña 10:111-119.

BLANCO, A. (1960): “Orientalia II”, Archivo Español de Arqueología XXXIII:5-43.

BLANCO, A. (1963): “Ajuar de una tumba de Cástulo”, Archivo Español de Arqueología XXXVI:40-70

BLASCO, M.C. (1987): “El Bronce Medio y Final”, 140 años de Arqueología Madrileña: 82-107. Madrid.

BLASCO, M.C. y ALONSO, M. A. (1983): “Aproximación al estudio de la Edad del Hierro en la provincia de Madrid", Homenaje al Profesor Martín Almagro Basch: 119-134. Madrid.

BLASCO, M.C.; y BAENA, J. (1989): "El yacimiento de La Capellana (Pinto, Madrid). Nuevos datos sobre las relaciones entre las costas meridionales y la Submeseta sur durante la Primera Edad del Hierro, Cuadernos de Prehistoria y Arqueología de la Universidad Autónoma de Madrid 16:211-231.

BLASCO, M.C.; BAENA, J.; MILLÁN, M.A.; BENÍTEZ, P.; ESPAÑA, E. y CALDERÓN, T. (1993): "El Hierro Antiguo en el alto Tajo, aproximación cultural y marco cronológico apoyado en cuatro fechas de termoluminiscencia del yacimiento de La Capellana", Madrider Mitteilungen 34:48-70.

BLASCO, M.C.; BAENA, J. y RECUERO, V. (1994): "Los asentamientos", M.C. Blasco (ed.) El horizonte campaniforme de la región de Madrid en el centenario de Ciempozuelos: 47-73

BLASCO, M.C. y BARRIO, J. (1986): "Excavaciones en dos nuevos asentamientos prehistóricos de Getafe (Madrid)" Noticiario Arqueológico Hispánico 27:75-142.

BLASCO, M.C.; LUCAS, R. y ALONSO, A. (1991): "Excavaciones en el poblado de la Primera Edad del Hierro del Cerro de San Antonio (T.M. de Madrid)", Arqueología, Paleontología y Etnografía 2: 7-159.

BLASCO, M.C.; SÁNCHEZ-CAPILLA, M.L. y CALLE, J. (1988): "Madrid en el marco de la Primera Edad del Hierro de la Península Ibérica", Cuadernos de Prehistoria y Arqueología de la Universidad Autónoma de Madrid 15:139-182.

BLASCO, M.C.; SÁNCHEZ-CAPILLA, M.L. y CALLE, J. (e.p.): "Materiales orientalizantes en la región de Madrid", IV Congreso Internacional e Estudios Fenicios y Púnicos (Cádiz,1995).

BLÁZQUEZ, J.M. y VALIENTE, J. (1981): Cástulo III (EAE 117). Madrid.

BLÁZQUEZ, J.M.; GARCÍA-GELABERT, M.P. y LÓPEZ, F. (1985): Cástulo V(Excavaciones Arqueológicas en España 140). Madrid.

CABRÉ, M.E. (1931): "El problema de la cerámica con incrustaciones de cobre y ámbar de Las Cogotas y la Península Ibérica", XVE Congrès International d'Anthropologie et d'Archeologie Préhistorique (Portugal 1930).

CALLEJO, C. y BLANCO, A. (1960): "Los torques de oro de Berzocana (Cáceres)", Zephyrus XI.

CERDEÑO, M.L. y GARCÍA-HUERTA, M.R. (1990): "Las necrópolis de incineración del Alto Jalón y el Alto Tajo", Necrópolis Celtibéricas. II Simposio sobre los Celtíberos: 75-92. Zaragoza.

CHAVES, F. y BANDERA, M.L. de la (1991): "Aspectos de la urbanística en Andalucía Occidental en los siglos VII-VI a.C. a la luz del yacimiento de Montemolín (Marchena, Sevilla)", Atti del II Congresso Internazionale di Studi Fenici e Punici (Roma 1987), II:691-714.

COELHO, A.; TAVARES, C. y BAPTISTA, A. (1984): "Deposito de fundidor do final da idade do Bronze do Castro de Senhora da Guia (Baiões, S. Pedro do sul, Viseu)", Lucerna. Homenagem a D. Domingo de Pinho Brandão: 73-109. Porto. 
COFFYN, A. (1985): Le Bronze Final atlantique dans la Péninsule Ibérique. París

CORREIA, V.H. (1993): "Os materias pré-romanos de Conimbriga e a presença fenicia no Baixo Mondego", Os fenicios no territorio Portugues (5-6 Junio 1992) Estudos Orientais, IV:229-283. Lisboa.

CRESPO. M.L. (1995): "Estructuras de habitación en Pico Buitre (Espinosa de Henares)", en R. Balbín, J. Valiente y M.T. Mussat (coords.): Arqueología en Guadalajara:163-178. Toledo.

DELIBES, G. (1993): Sal y jefaturas: una reflexión sobre el yacimiento del Bronce Antiguo de Santioste, en Villafáfila (Zamora), Brigecio 3:33-46.

ESCACENA, J.L. y RODRÍGUEZ, M. (1988): "La Marismilla ¿Una salina neolítica en el Bajo Guadalquivir?", Revista de Arqueología IX:15-25.

Evaluación de Recursos Agrarios. Mapa de cultivos y Aprovechamientos. Escala 1:50000. Hoja 605. Aranjuez. Madrid, 1982.

FERNÁNDEZ MARTÍNEZ, V.M.; HORNERO, E. y PÉREZ, J.A. (1994): “El poblado ibérico del 'Cerro de las Nieves' (Pedro Muñoz). Excavaciones 1984-1985”, en J. Sánchez, c. Galán, A. Caballero, C. Fernández y M.T. Mussat (coords.): Arqueologia en Ciudad Real:111-129. Toledo.

FERNÁNDEZ RODRÍGUEZ, CABALLERO, A. y JUAN, A. de (1995): "Constantes de poblamiento en Alarcos", J. Zozaya (ed.): Alarcos, el fiel de la balanza:28-40.

FERNÁNDEZ-MIRANDA, M. (1986): "La estela de Las Herencias (Toledo)", Estudios en Homenaje al Dr. Antonio Beltrán Martínez:463-475. Zaragoza.

FERNÁNDEZ-MIRANDA, M. y PEREIRA, J. (1992): "Indigenismo y orientalización en la tierra de Talavera", Actas de las Primeras Jornadas de Arqueología de Talavera y su Tierra:47-94. Toledo.

FLETCHER, D. (1953): "Origen y cronología de los vasos ibéricos de bordes dentados", Saitabi 2.

GALÁN, E. (1993): Estelas, paisaje y territorio en el Bronce Final del Suroeste de la Península Ibérica = Complutum Extra, 3. Madrid.

GALÁN, E. y MARTÍN, A.M. (1992): "Megalitismo y zonas de paso en la cuenca extremeña del Tajo", Zephyrus 44-45:193-205.

GALÁN, E. y RUIZ-GÁLVEZ, M.L. (e.p.): "Rutas ganaderas, transterminancia y caminos antiguos: el caso del Occidente peninsular entre el Calcolítico y la Edad del Hierro", en P. Cressier y J. Gómez Pantoja (coords): Aspectos del pastoreo en la Península Ibérica.

GARCÍA Y BELLIDO, A. (1964): "Nuevos jarros de bronce tartésicos”, Archivo Español de Arqueología XXXVII:50-80.

GARCÍA CARRILLO, A. y ENCINAS, M. (1990): "Cerámicas incisas del conjunto funerario 44-45 de las necrópolis de Las Esperillas (Santa Cruz de la Zarza, Toledo)", Necrópolis Celtibéricas. II Simposio sobre los Celtíberos: 317-326. Zaragoza.

GARCÍA SANZ, C. (1990): "El urbanismo protohistórico de Huelva", Huelva Arqueológica X-XI, 3: 143-176.

GARCÍA SOTO, E. (1990): "Las necrópolis de la Edad del Hierro en el Alto Valle del Duero", Necrópolis Celtibéricas. II Simposio sobre los Celtíberos: 13-38. Zaragoza.

GARCÍA SOTO, E. y ROSA, R. de la (1995): "Consideraciones sobre el poblamiento en la ribera soriana del Duero dunarte la I Edad del Hierro", Poblamiento Celtibérico. III Simposio sobre los Celtíberos: 83-92. Zaragoza.

GARRIDO, R. y MUÑOZ, K. (e.p.): "La cuenca media del río Tajo en el panorama del Calcolítico y los comienzos de la Edad del Bronce de la Península Ibérica", II Congreso de Arqueología Peninsular (Zamora, 1996).

GARRIDO, J.P. y ORTA, M.E. (1978): Excavaciones en la necrópolis de La Joya $\left(3^{a}, 4^{a}\right.$ y $5^{a}$ campañas). Excavaciones Arqueológicas en España, 96. Madrid.

GARRIDO, J.P. y ORTEGA, J. (1994): "A propósito de unos recientes hallazgos cerámicos griegos arcaicos y orientalizantes en Huelva", Huelva Arqueológica XIII, 1:49-66. 
GASSUL, P. (1982): “Los soportes del Bajo Guadalquivir. Intento de clasificación”, Madrider Mitteilungen, 23: 62-95.

GIL-MASCARELL, M. y PEÑA, J.L. (1989): "La fíbula «ad occhio» del yacimiento de La Mola d'Agres", Saguntum 22: 125-142.

GONZÁLEZ-PRATS, A. (1983): Estudio arqueológico del poblamiento antiguo de la Sierra de Crevillente (Alicante). Alicante.

GONZÁLEZ-PRATS, A. (1985): “La Peña Negra II-III. Campaña de 1978-79”, Noticiario Arqueológico Hispánico 21: 7-155.

GONZÁLEZ-PRATS, A. (1992): “Una vivienda metalúrgica en la Peña Negra (Crevillente, Alicante). Aportación al conocimiento del Bronce Atlántico en la Península Ibérica", Trabajos de Prehistoria 49: 243-257.

GONZÁLEZ-PRATS, A. y RUIZ-GÁLVEZ, M.L. (1986): "La metalurgia de Peña Negra en su contexto del Bronce Final del Occidente europeo", XIX Congreso Nacional de Arqueología: Zaragoza.

JIMÉNEZ DE GREGORIO, F. (1955): “Fíbulas de tipo hispánico en Azután”, Archivo Español de Arqueología XXVIII:185-187.

JIMÉNEZ DE GREGORIO, F. (1962-86): Los pueblos de la provincia de Toledo hasta finales del siglo XVIII. Población, sociedad, economía, historia. Toledo.

JIMÉNEZ DE GREGORIO, F. (1966): "Hallazgos arqueológicos en la provincia de Toledo", Archivo Español de Arqueología XXXVIII:174-186.

LEBLIC, V. (1994): Medicina Popular en la Provincia de Toledo, Temas Toledanos, 78, Toledo.

LÓPEZ, J.J.; BUENO, P.; RUIZ, J.A. y PRADA L. de (1996): Tartesios y fenicios en Campillo, El Puerto de Santa María, Cádiz. Una aportación a la cronología del Bronce Final en el Occidente de Europa. Cádiz.

LÓPEZ, L. y ARROYO, F. (1983): “Antiguas salinas de la comarca de Aranjuez", Estudios Geográficos XLIV:339-370.

LÓPEZ, L.; MADRIGAL, A.; MUÑOZ, K. y ORTIZ, J.R. (e.p.): "La transición entre el Bronce Final y la Primera Edad del Hierro en la Cuenca Media del río Tajo: el yacimiento de Camino de las Cárcavas (Aranjuez, Madrid)", II Congreso de Arqueología Peninsular (Zamora, 1996).

MADOZ, P. (1848-1850): Diccionario geográfico-estadístico-histórico de España y sus posesiones de Ultramar. Madrid.

MALLOWAN, J. (1966): The Nimrud Ivories. Londres.

MAROTO, M. (1990): Fuentes para el estudio de la Arqueología de la provincia de Toledo. Toledo.

MARTÍN DE LA CRUZ, J.C. (1987): El Llanete de Los Moros, Montoro, Córdoba (EAE 151). Madrid.

MÉNDEZ, A. y VELASCO, F. (1984): "La Muela de Alarilla. Un yacimiento de la Edad del Bronce en el Valle Medio del río Henares", Revista de Arqueología 37:6-15.

MOLINA, F. (1983): "Nuevas aportaciones para el estudio del origen de la cultura ibérica de la Alta Andalucía. La campaña de 1980 en el Cerro de los Infantes". XVI Congreso Nacional de Arqueología (Murcia 1982): 689-707. Zaragoza.

MORENO, F. (1990): “Notas al contexto de Arroyo Manzanas (Las Herencias, Toledo)". Actas del I Congreso de Arqueología de Toledo: 275-308. Toledo.

MUÑOZ, K. (1993): "El poblamiento desde el Calcolítico a la Primera Edad del Hierro en el Valle Medio del río Tajo", Complutum 4:321-336.

MUÑOZ, K.; GARCÍA, T. e IZQUIERDO, D. (1995): “Aportaciones al estudio de la Edad del Cobre en la cuenca media del río Tajo", Boletín del Seminario Español de Arte y Arqueología LXI:31-50.

MUÑOZ, K. y ORTEGA, J. (1996): "La transición Primera-Segunda Edad del Hierro en el Bajo Henares: las cabañas de «Los Pinos» (Alcalá de Henares, Madrid)", Actas del V Encuentro de Historiadores del Valle del Henares (Guadalajara, 1996): 31-43. Guadalajara. 
PACHÓN, J.A.; CARRASCO, J. y ANÍBAL, C. (1989-90): “Decoración figurada y cerámicas orientalizantes. Estado de la cuestión a la luz de los nuevos hallazgos", Cuadernos de Prehistoria de la Universidad de Granada 14-15: 208-272.

PEREIRA, J. (1990): "Presencia de elementos orientalizantes en el sector occidental de la Carpetania", Toledo y Carpetania en la Edad Antigua: 39-54.

PEREIRA, J. (1994): "La transición del Bronce Final al Hierro en la Meseta Sur", Actas del Simposio «La Edad del Bronce en Castilla-La Mancha» (Toledo, 19-21 de diciembre, 1990): 37-85. Toledo.

PEREIRA, J. y ÁLVARO, E. de (1988): "Una tumba de la transición Bronce-Hierro en la Meseta Sur: El Carpio (Belvis de la Jara, Toledo)", I Congreso de Historia de Castilla-La Mancha III: 279-289. Toledo.

PEREIRA, J. y ÁLVARO, E. de (1990): "El enterramiento de la Casa del Carpio, Belvis de la Jara (Toledo)", Actas del I Congreso de Arqueología de la Provincia de Toledo:215-234. Toledo.

PÉREZ DE BARRADAS, J. (1936): "Fondos de cabaña de la Edad del Hierro del Puente Largo del Jarama", Anuario de Arqueología Madrileña IV-VI (1933-1935):185-189.

PERNIA, A. y LEIRA, R. (1992): "Excavación de urgencia en el Arenero de Soto II (P.K. 5,360 al P.K. 5,380 del Tren de Alta Velocidad Madrid-Sevilla)", Arqueología, Paleontología y Etnografía 3:1 19-130. Madrid.

PORRES, J.; RODRÍGUEZ, H. y SÁNCHEZ, R. (1986): Descripciones del Cardenal Lorenzana (Archivo Diocesano de Toledo). Toledo.

ROSA, R. de la y GARCÍA SOTO, E. (1995): "Cerro Ogmico, un yacimiento de Campos de Urnas en el Alto Jalón", Poblamiento Celtibérico. III Simposio sobre Celtíberos: 265-274. Zaragoza.

RUIZZAPATERO, G. (1985): Los Campos de Urnas del Noreste de la Península Ibérica, Tesis Doctoral, Universidad Complutense.

RUIZ MATA, D. (1979): "El Bronce Final -fase inicial- en Andalucía Occidental. Ensayo de definición de sus cerámicas", Archivo Español de Arqueología 52:3-30.

RUIZ MATA, D. (1979): "La cerámicas del Bronce Final. Un soporte tipológico para delimitar el tiempo y el espacio tartésico", Tartesos 25 años después. Actas del Congreso conmemorativo del V Symposium Internacional de Prehistoria Peninsular:265-313.

RUIZ ZAPATERO, G. y LORRIO, A. (1988): "Elementos e influjos de tradición de «Campos de Urnas» en la Meseta sudoriental", I Congreso de Historia de Castilla-La Mancha III:257-261. Toledo.

RUIZ-GÁLVEZ, M.L. (1992): "La novia vendida: orfebrería, herencia y agricultura en la Prehistoria de la Península Ibérica", Spal 1:219-251.

RUIZ-GÁLVEZ, M.L. (1993): "El Occidente de la Península Ibérica, punto de encuentro entre el Mediterráneo y el Atlántico a fines de la Edad del Bronce", Complutum 4:41-68.

SAN NICOLÁS, M.P. (1975): "Las cáscaras de huevo de avestruz fenicio-púnicos en la Península Ibérica y Baleares", Cuadernos de Prehistoria de la Universidad Autónoma de Madrid 2:75:100.

SÁNCHEZ-CAPILLA, M.L. y CALLE, J. (1996): "Los Llanos II: un poblado de la Primera Edad del Hierro en las terrazas del Manzanares (Getafe)", Reunión de Arqueología Madrileña:254-257. Madrid.

SPINDLER, D.; CASTELLO, A. de;ZBYZEWSKI, G. y VEIGA O. de (1973-74): "Le monument a coupole de l'âge du bronze final de la Roça do Casal do Meio (Calhariz)", Comunicaçoes dos Serviços Geologicos de Portugal 57:91-153.

TORRES, M. (1996): "La cronología de los túmulos A y B de Setefilla", Complutum 7:147-162.

VALIENTE, J. (1984): "Pico Buitre (Espinosa de Henares, Guadalajara). La transición del Bronce Final al Hierro en el Alto Henares”, Wad-al-Hayara 11:9-58. 


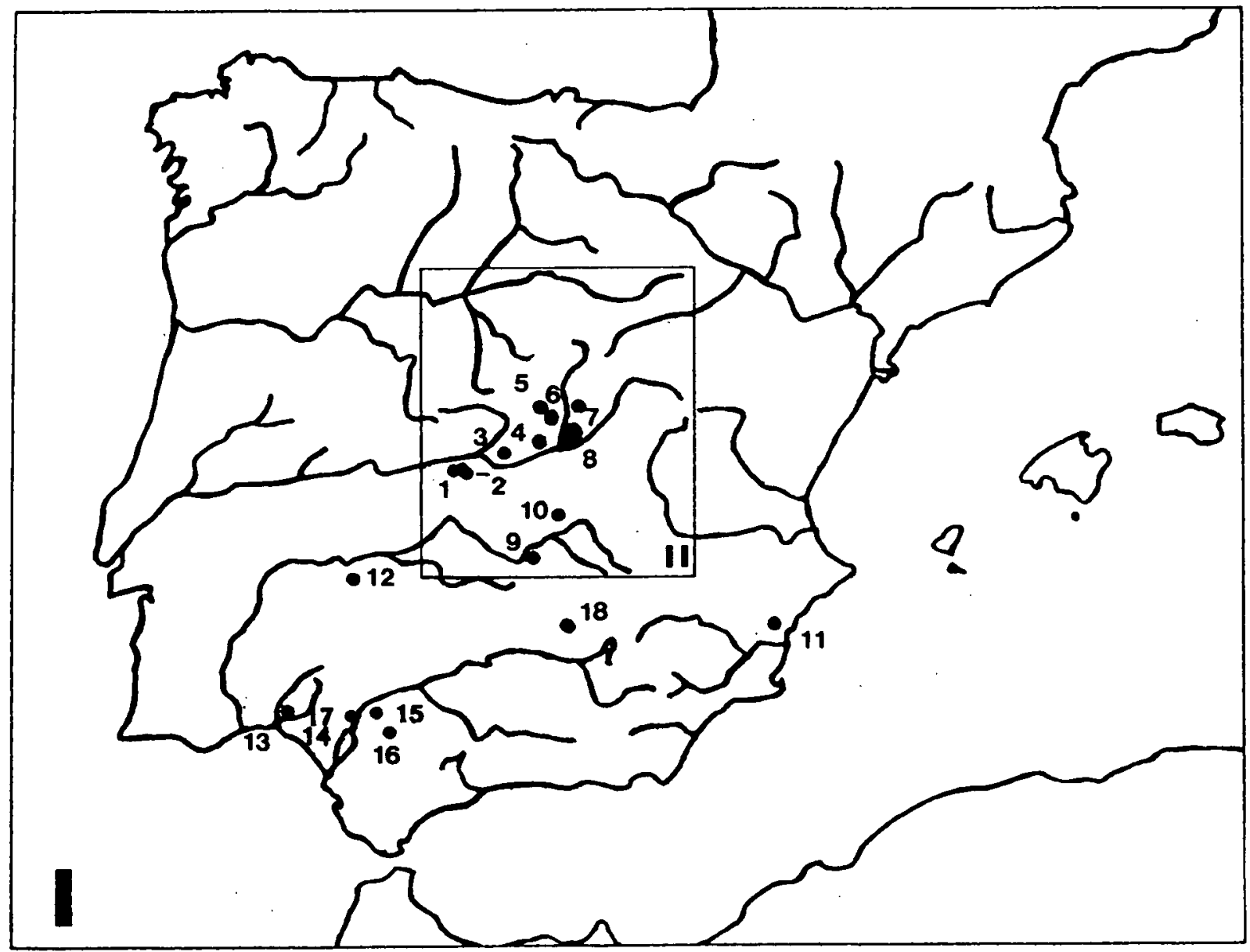

Figura 1. Yacimientos del ámbito peninsular mencionados en el texto: 1.- Azután; 2.- Las Herencias y Las Fraguas; 3.- Ronda y El Carpio; 4.- Camino Pucheros 1 y 2; 5.- Venta de la Victoria; 6.- Perales del Río; 7.- Ecce Homo; 8.- Puente Largo de Jarama; 9.- Alarcos; 10.- Pedro Muñoz; 11.- Peña Negra; 12.- Medellín; 13.- Huelva; 14.-Campillo; 15.- Setefilla; 16.- Montemolín; 17.- Carmona; 18.- Cástulo. 


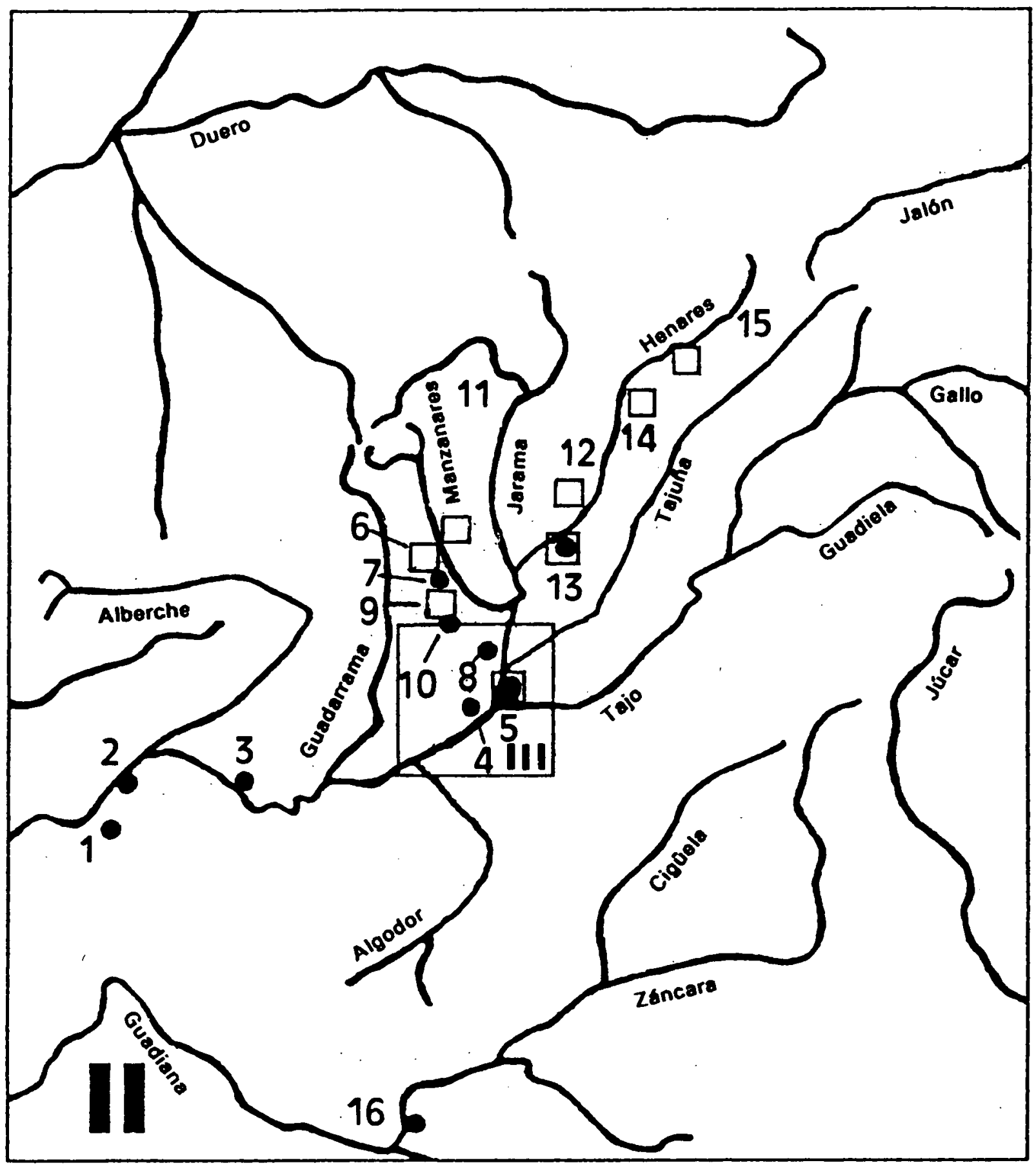

Figura 2.- Yacimientos en torno al Tajo Central con elementos orientalizantes ( $\bullet$ y estructuras de habitación ( $\square$ ) del Bronce Final y Primera Edad del Hierro: 1.- Azután; 2.- Las Herencias y Las Fraguas; 3.- Ronda y El Carpio; 4.- Camino Pucheros 1 y 2; 5.- Puente Largo de Jarama; 6.- Sector III de Getafe; 7.- Venta de la Victoria; 8.- Las Capellana; 9.- Arenero de Soto II; 10.- Perales del Río; 11.- Cerro de San Antonio; 12.- Los Pinos; 13.- Ecce Homo; 14.- Alarilla; 15.- Pico Buitre; 16.- Alarcos. 


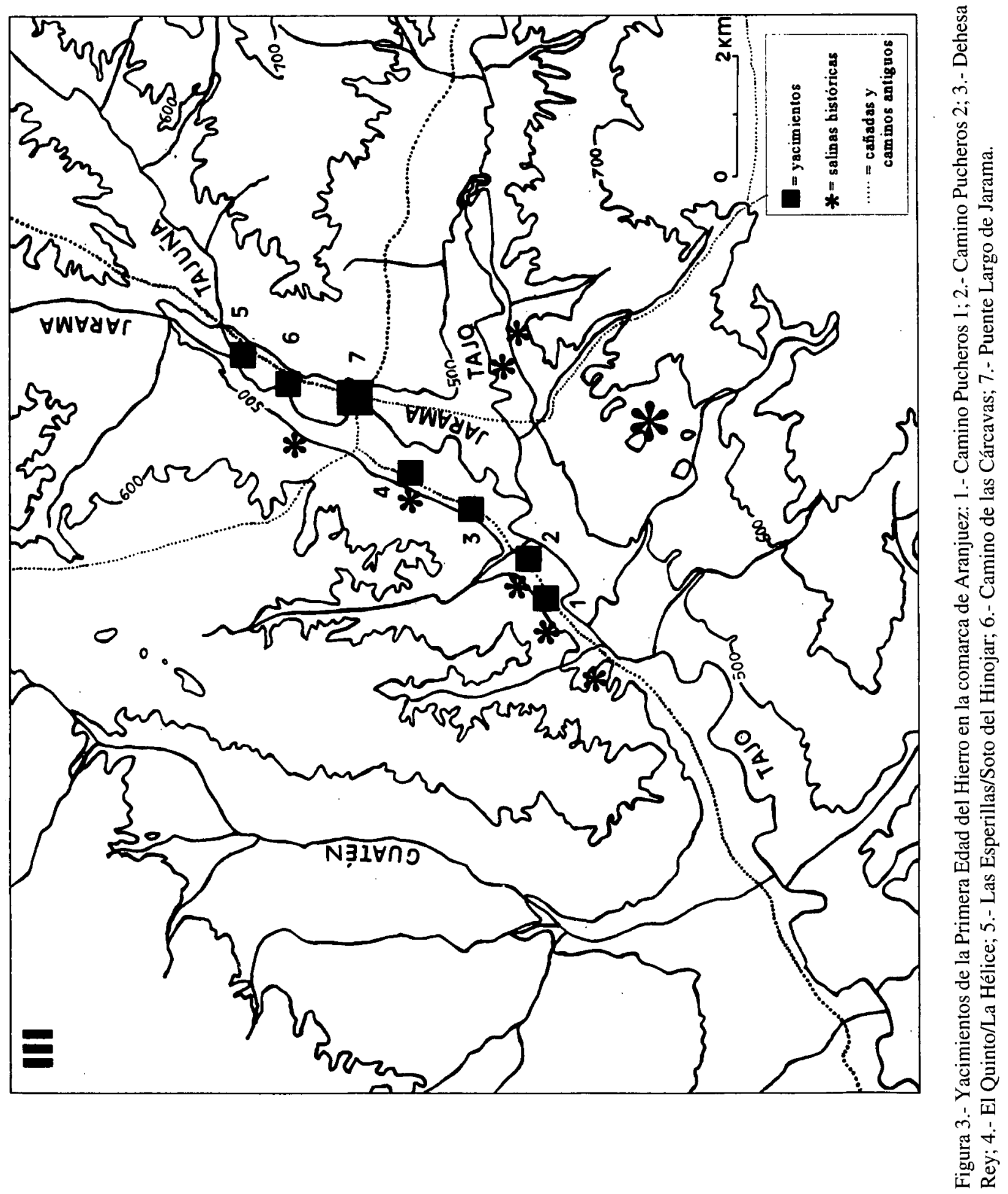




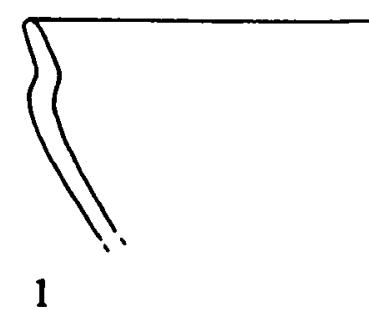

1

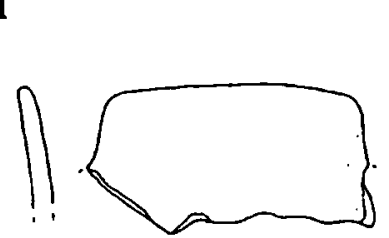

3

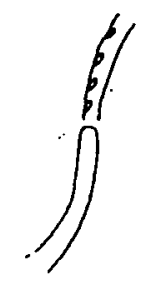

4
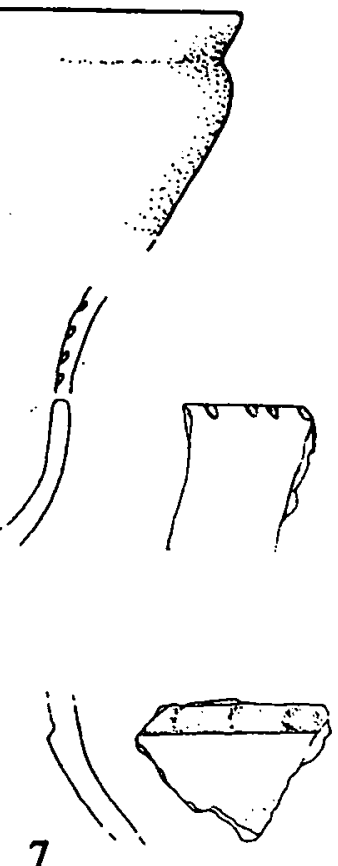

6
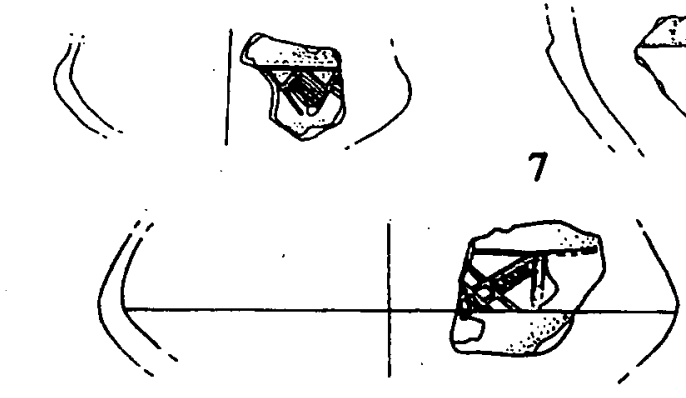

is

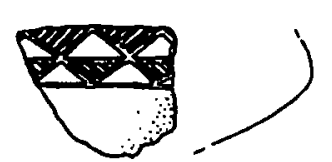

10

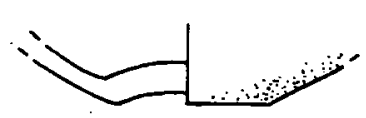

11

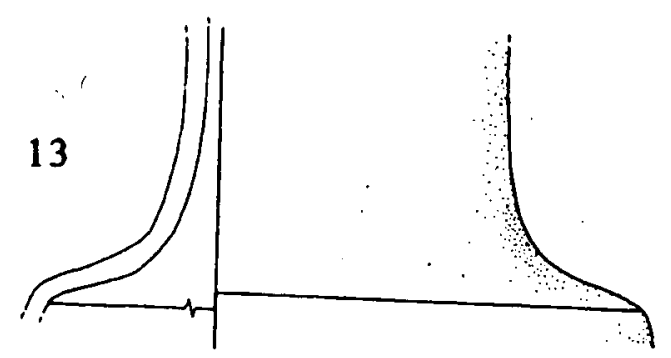

14

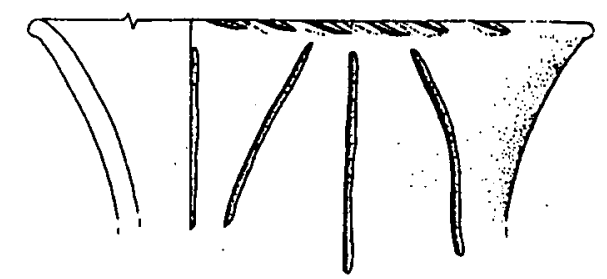

Figura 4: Materiales cerámicos del yacimiento de Puente Largo de Jarama. 

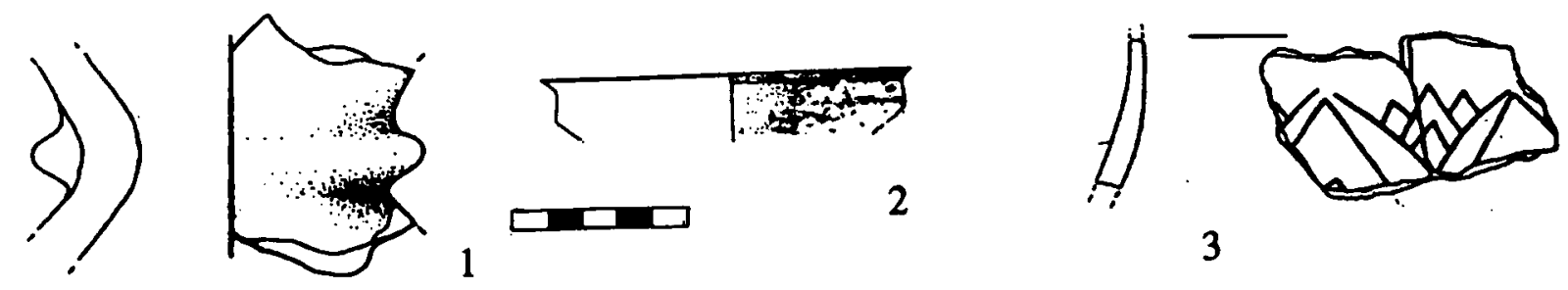

A

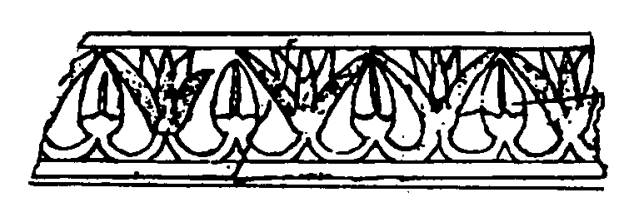

1

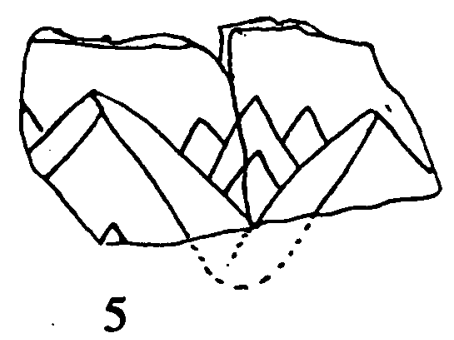

5

4
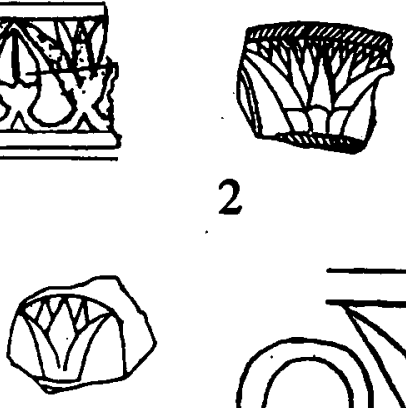

2

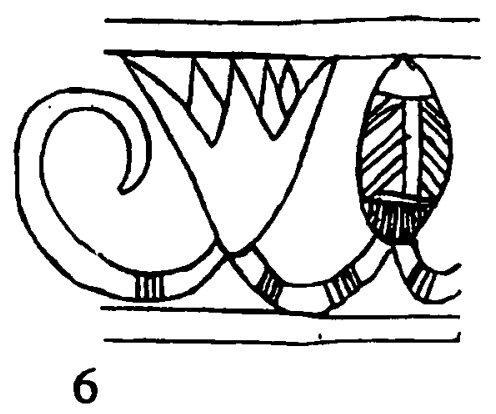

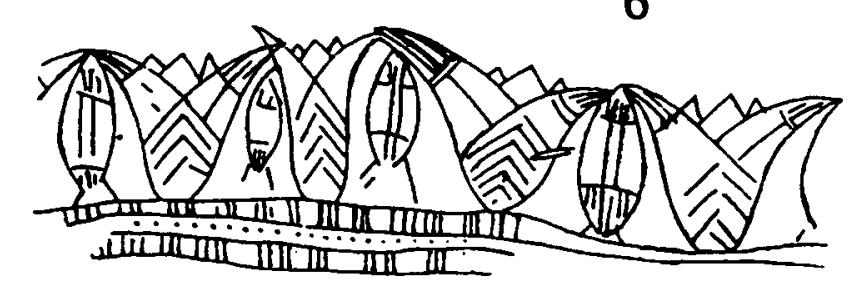

7

B

Figura 5 

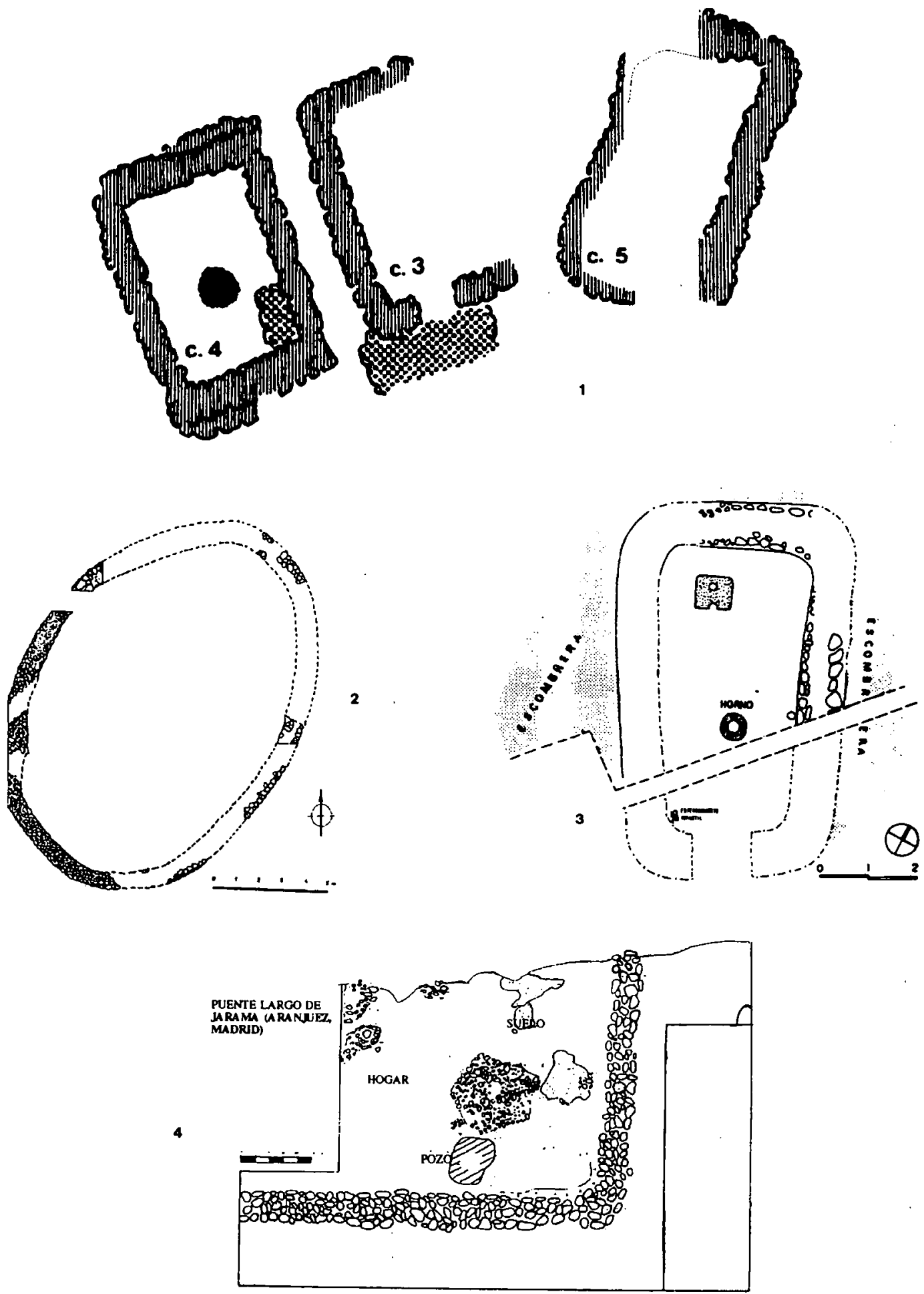

Figura 6: Estructuras de planta oval o rectangular con esquinas redondeadas de la primera mitad del Primer Milenio a.C. peninsular: 1.- Acinipo (según Aguayo y otros 1991); 2.- Peña Negra (según González-Prats 1992); 3.- Montemolín (según Chaves y Bandera 1991); 4.- Puente Largo de Jarama. 

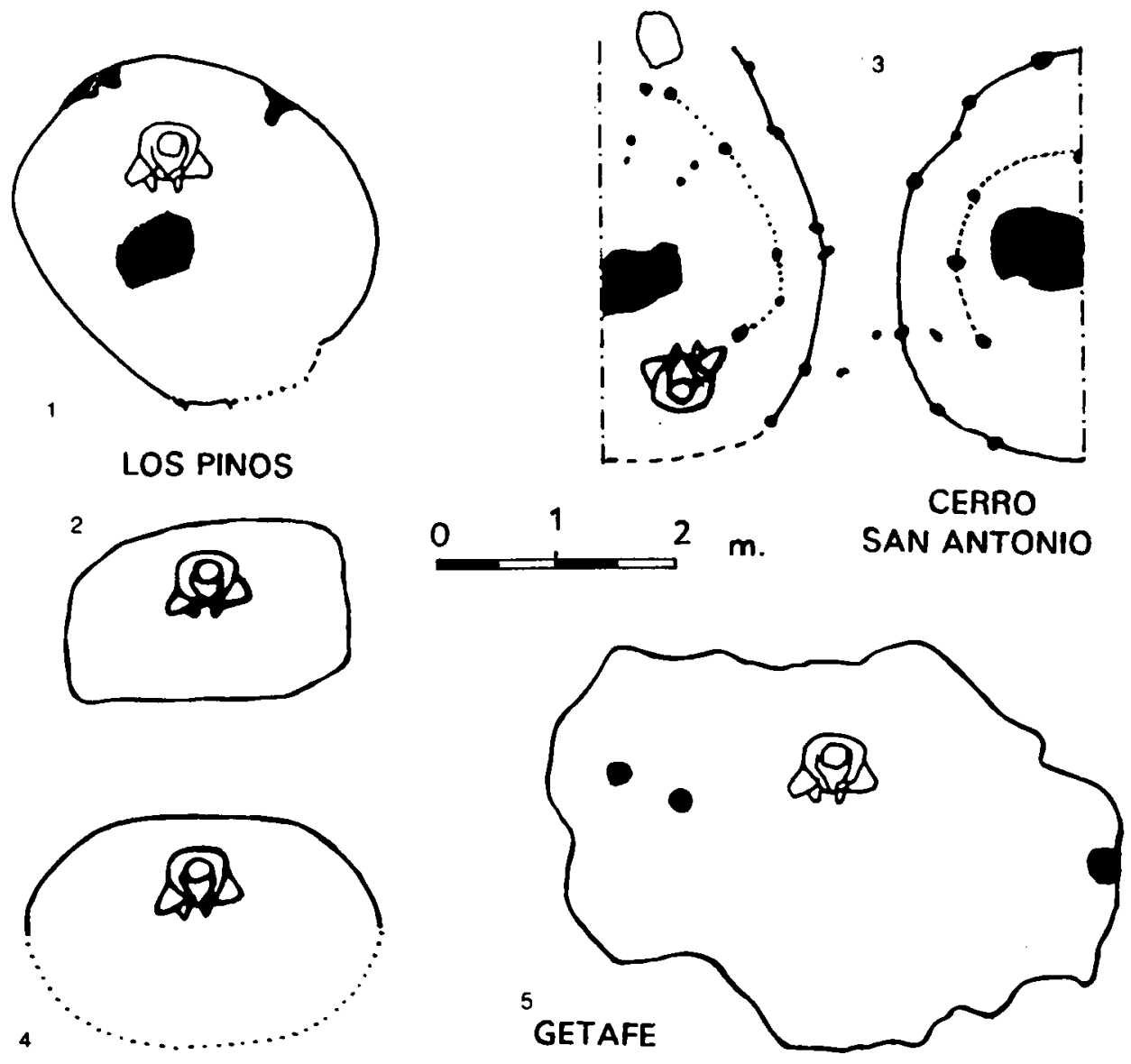

\section{CERRO SAN ANTONIO}
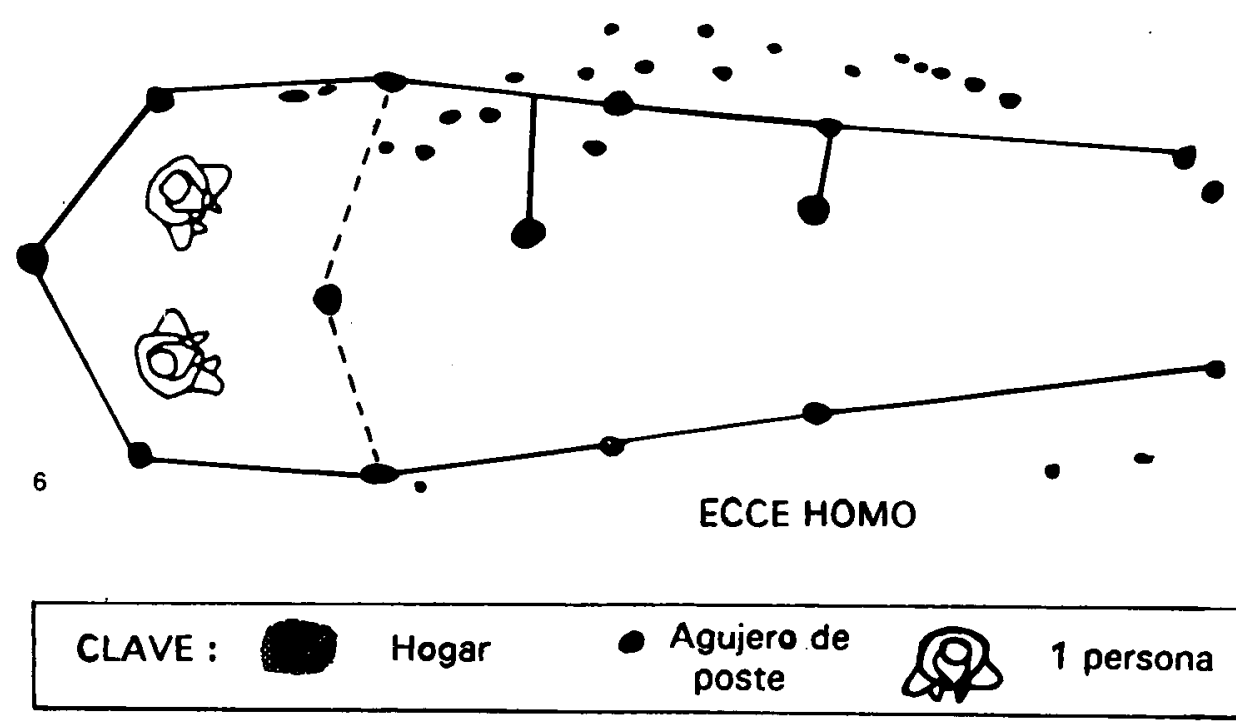

Figura 7: Plantas de cabañas de la I Edad del Hierro en la Cuenca Media del Tajo y Valle del Henares. 